\title{
Phosphorus-Based lonic Liquid as Dual Function Promoter Oriented Synthesis of Efficient VPO Catalyst for Selective Oxidation of n-butane
}

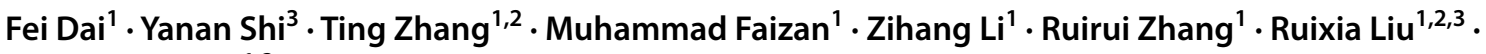 \\ Suojiang Zhang ${ }^{1,2}$
}

Received: 11 February 2020 / Accepted: 16 June 2020 / Published online: 24 June 2020

(c) The Author(s) 2020

\begin{abstract}
Vanadium phosphorus oxide (VPO) catalysts promoted by phosphorus-based ionic liquids (ILs) as structure directing agent and promoters have been innovatively synthesized and investigated for selective oxidation of n-butane to maleic anhydride (MA). The catalytic performances showed that the IL addition notably improved the n-butane conversion and MA selectivity, during which the optimized 3\%IL-VPO catalyst exhibited the maximum MA yield of 59.2\% that is much better than that of blank VPO with $49.4 \%$ MA yield under the same reaction conditions. XRD, FI-IR, Raman, SEM, TG, BET, XPS and $\mathrm{H}_{2}$-TPR techniques were utilized combinatorically to elaborate the synergistic effect of cations and anions of ILs. Results demonstrated that IL-cations oriented synthesis of VPO precursor showing a vertically intercrossed slice structure morphology having smaller lamellar thickness. Correspondingly, it notably enhanced the specific surface area of the VPO catalysts and exposed the more active surface of $(\mathrm{VO})_{2} \mathrm{P}_{2} \mathrm{O}_{7}$ after activation. Meanwhile, IL-anions as promoters largely modulated the $\mathrm{P} / \mathrm{V}$ ratio, valence state of $\mathrm{V}$ and oxygen species amounts on the surface of VPO catalyst, etc. All of these influence factors were subsequently discussed in detail and correlated to the catalytic performance of VPO catalysts.
\end{abstract}

Fei Dai and Yanan Shi have contributed equally to this work.

Ruixia Liu

rxliu@ipe.ac.cn

$\triangle$ Suojiang Zhang

sjzhang@ipe.ac.cn

1 Beijing Key Laboratory of Ionic Liquids Clean Process, State Key Laboratory of Multiphase Complex System, Institute of Process Engineering, Chinese Academy of Sciences, Beijing 100190, People's Republic of China

2 University of Chinese Academy of Sciences, Beijing 100049, People's Republic of China

3 School of Chemical Engineering and Energy, Zhengzhou University, Zhengzhou 45001, China 


\section{Graphic Abstract}

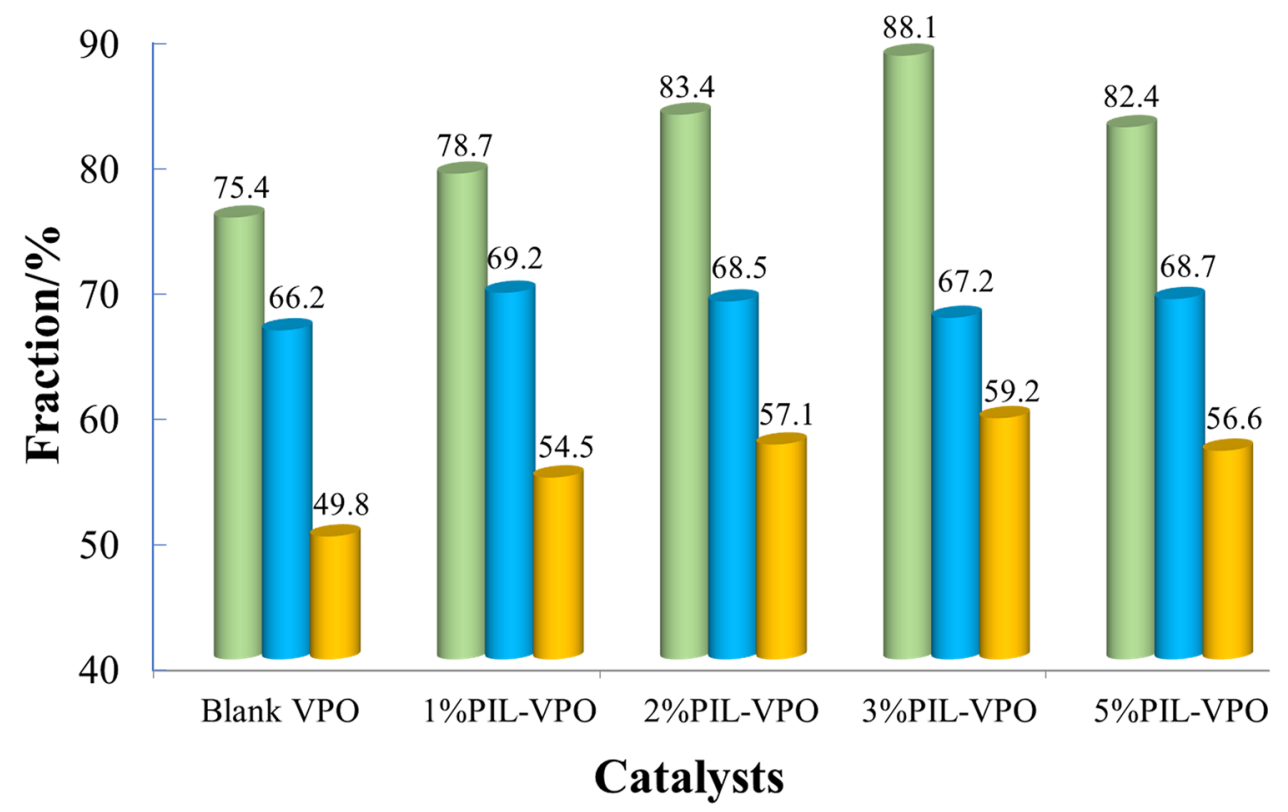

Catalyst performance of all the catalysts

Keywords Ionic liquid $\cdot \mathrm{N}$-butane oxidation $\cdot$ Vanadium phosphorus oxide $\cdot$ Maleic anhydride

\section{Introduction}

Maleic anhydride (MA) is a vital basic chemical material that is extensively applied in the production of unsaturated resins, coating, pesticides, medicines, etc. MA is primarily produced in industry by n-butane selective oxidation process, in which vanadium phosphorus oxide catalysts (VPO) are viewed as the most successful catalysts for this reaction [1-3]. Up to now, tremendous efforts have always been devoted to the research of VPO catalyst in terms of its crystal structure, morphology and surface chemistry as well as reaction mechanism, etc. However, it is still a great challenge to break through the low selectivity towards MA under high n-butane conversion owing to the complex catalytic reaction involving three oxygen molecular insertions and transfer of 14 electrons [4, 5]. Therefore, developing efficient VPO catalyst has always been the research hotspot from an economic and environmental point of view [4, 6-10].

Extensive researches indicated that addition of metal dopants [7, 11-19], organic structural directing agent [20-23] and surfactant [24] during the preparation of VPO were usually employed as effective strategies to enhance its catalytic performance by modulating the crystal structure, morphology as well as chemical properties of the surface (such as P/V ratio, valence state of V, amounts of lattice oxygen, etc.). Recently, metal-based ionic liquids (ILs) acting as additives and promoters were firstly proposed and applied in the synthesis of VPO catalyst for selective conversion of n-butane in our previous work [25, 26], the ILs including iron metal was observed to have largely increased the proportion of active phase $(\mathrm{VO})_{2} \mathrm{P}_{2} \mathrm{O}_{7}$ and induced a great change in structure morphology of VPO owing to their synergistic action between the metal anions and structureguided cations in ILs, the obtained VPO catalyst exhibited excellent performance with high conversion of n-butane and selectivity of MA. In the light of the enlightenment from ILs, the efforts were further made to employ deep eutectic ILs as structural modifier and crystal induced agent to assist the preparation of VPO and obtained a good catalytic behavior [27]. The aforementioned work provide a new strategy for the development of efficient VPO catalyst by utilizing ILs as structural directing agent or promoters in view of their unique physical properties, such as good thermal stability, negligible volatility, high polarity and excellent dissolving ability, etc.

In addition, a significant number of literatures and patents revealed that the phosphorus as body element in VPO is dominant contributor affecting the catalytic activities of n-butane oxidation [28-33]. On the one hand, the phosphorus is usually deemed to have the capability to regulate the proportion of $\mathrm{V}^{4+} / \mathrm{V}^{5+}$ crystal phase in VPO and to stabilize $\mathrm{V}^{4+}$ specie by means of preventing the overoxidation 
of $\mathrm{V}^{4+}$ species to $\mathrm{V}^{5+}[25,26]$. Generally, the valence state of $\mathrm{V}$ plays a vital role in the improvement of VPO catalyst performance. On the other hand, the $\mathrm{O}(1)=\mathrm{P}$ on the $\mathrm{VPO}\left(\mathrm{V}^{\mathrm{V}} \mathrm{OPO}_{4}\right)$ surface is considered as the active center for initiating the VPO chemistry through extraction of $\mathrm{H}$ from $\mathrm{C}-\mathrm{H}$ bonds, and the ability of $\mathrm{O}(1)=\mathrm{P}$ in cleaving $\mathrm{C}-\mathrm{H}$ bonds is closely associated with its strong basicity together with abundant reduction potentials [32]. Furthermore, the activity-selectivity of n-butane conversion largely hinges on the $\mathrm{P} / \mathrm{V}$ atomic ratio of the catalyst and an irreversible loss of phosphorus in long-term operation of commercial process was responsible for the catalyst deactivation [34]. Considering the above fact, a vital conclusion can be drawn that the addition of phosphorus in VPO will have a massive impact on adjusting its crystal structure and surface chemistry. Meanwhile, inspired by structural orientation effect from ILs, designing and synthesizing a phosphorus-based ILs with the dual function of a phosphorus-containing anion and structure-oriented cations seems to be a feasible method to assist the synthesis of efficient VPO catalyst.

Thus, the current work attempts to modify VPO catalyst though the phosphorus-based ILs as structure directing agent and promoters, in which 1-butyl-3-methylimidazolium hexafluorophosphate $\left([\mathrm{BMIM}] \mathrm{PF}_{6}\right)$ with different contents are selected as typical ILs, and blank VPO was also prepared and tested for comparison purpose. Besides, the physicochemical properties of the VPO proposed were also systematically investigated in this work to understand the intrinsic effect of ILs in dept. This work aims to provide a promising route to the synthesis of VPO catalysts for highly selective oxidation of n-butane to MA.

\section{Experimental}

\subsection{Chemicals and Material}

Vanadium pentoxide $\left(\geq 99.5 \% ; \mathrm{V}_{2} \mathrm{O}_{5}\right)$ with particle size in the range of $150-180 \mu \mathrm{m}$ was provided by Nanyang Co., Ltd., Isobutyl alcohol ( $\geq 99.5 \%)$ and Benzyl alcohols $(\geq 99.5 \%)$ used were all obtained from Tianjin Chemical Reagent Factory. The phosphoric acid $\left(\geq 85 \mathrm{wt} \%, \mathrm{H}_{3} \mathrm{PO}_{4}\right)$ was purchased from Guoyao Chemical Reagent Co., Ltd., China. The $[\mathrm{BMIM}] \mathrm{PF}_{6}(\geq 99.5 \%)$ was produced by Shanghai Chengjie Chemical Co.

\subsection{Catalysts Synthesis}

The blank VPO precursor was prepared in this work via organic route in the following way [35]: the $\mathrm{V}_{2} \mathrm{O}_{5}(20 \mathrm{~g})$ was reacted with benzyl alcohol $(40 \mathrm{~mL})$ in the solvent of isobutanol $(160 \mathrm{~mL})$ by refluxing at $383 \mathrm{~K}$ for $4 \mathrm{~h}$, the $\mathrm{H}_{3} \mathrm{PO}_{4}$ $(15.6 \mathrm{~mL}, \mathrm{P} / \mathrm{V}$ ratio $=1.04)$ was then added and further refluxed for $10 \mathrm{~h}$ at $383 \mathrm{~K}$ under the mechanical stirring device (SCILOGEX, OS20-Pro) with $350 \mathrm{rpm} / \mathrm{min}$. Noting that the reflux without water removal was performed by strictly controlling the reflux velocity of fluid via stopwatch counting, which conformed that all the tests were carried out in the identical conditions. Subsequently, the slurry obtained was cooled naturally and the solid phase was collected by the vacuum filtration for approximately $1 \mathrm{~h}$ and washed with ethanol for four times to make sure that the organic residues were removed thoroughly. Ultimately, the obtained solid was dried in ambient atmosphere at $393 \mathrm{~K}$ for $12 \mathrm{~h}$ by electrothermal blowing dry box to obtain the final blank VPO precursor. For IL-doped VPO precursors, the synthesis approach was kept same with the undoped

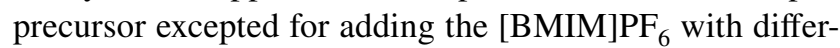
ent desired amounts (IL/mixed alcohol volume ratio $=0.01$, $0.02,0.03$ and 0.05 , mixed alcohol refers to the mixture of benzyl alcohol and iso-butanol) into $\mathrm{V}_{2} \mathrm{O}_{5}$ /alcohol mixture initially. Finally, the undoped and IL-doped VPO precursors were named as Blank-PVPO and xIL-PVPO, respectively, in which $\mathrm{x}$ represents the IL/alcohol volume ratio.

All VPO precursors powder prepared were further compressed into tablets by using the automatic tablet press (PCD 20S, Tianjing Pinchuang Co., Ltd.). Afterwards, these tablets were cracked by crusher into particles with different sizes, the particles with 20-40 mesh were sieved and used as VPO precursors for the subsequent experimental testing. Around $4.5 \mathrm{~g}$ of precursor was activated in-situ each time under the $703 \mathrm{~K}$ for $12 \mathrm{~h}$ in fixed bed microreactor with internal diameter of $10 \mathrm{~mm}$ and tube length of $80 \mathrm{~cm}$, during which the mixture gas of $1.5 \% \mathrm{n}$-butane in air with gas hourly space velocity (GHSV) of $2500 \mathrm{~h}^{-1}$ was flowed into reactor to keep the butane conversion in the range of $80-88 \%$. Correspondingly, the various activated VPO catalysts were donated as Blank VPO and xIL-VPO, respectively.

\subsection{Catalysts Evaluation}

The fixed bed microreactor (with internal diameter of $10 \mathrm{~mm}$ and tube length of $80 \mathrm{~cm}$ ) was used to test the catalytic performance of activated catalysts in terms of n-butane conversion and MA selectivity, in which the reaction temperature was kept in the range of $653-703 \mathrm{~K}$. The total of $4.5 \mathrm{~g}$ catalyst $(\sim 5 \mathrm{ml})$ with optimized amount was loaded in the isothermal zone of the reactor, where the height of catalyst bed is around $6 \mathrm{~cm}$. Besides, the maximum hot-spot temperature does not exceed $10{ }^{\circ} \mathrm{C}$ under the stable reaction runs for catalysts undiluted and all the experiments were carried out under the same conditions. The thermocouple was located in the center of the catalyst bed to monitor the reaction temperature. All the evaluation experiments eliminated the influence of external and internal diffusion by optimizing the loading volume and mass of catalyst. The gas mixture 
of $1.5 \% \mathrm{n}$-butane in air was flowed into reactor and the flow volume with GHSV of $2000 \mathrm{~h}^{-1}$ was controlled by a mass flow controller. After reaction, the exhaust was analyzed via an on-line gas chromatography (Shimadzu GC-2010 plus), the detailed analysis procedure has been described in our previous work [35]. The catalytic performance was calculated by the n-butane conversion, the MA selectivity and yield, which were listed as follows:

Conversion of $\mathrm{C}_{4} \mathrm{H}_{10}=\frac{C_{4} H_{10 \mathrm{in}, \mathrm{mol}}-C_{4} H_{10 \mathrm{out}, \mathrm{mol}}}{C_{4} H_{10 \mathrm{in}, \mathrm{mol}}}$

Selectivity of MA $=\frac{M A_{\text {out }, \text { mol }}}{C_{4} H_{10 \mathrm{in}, \mathrm{mol}}-C_{4} H_{10 \mathrm{out}, \mathrm{mol}}}$

Yield of MA $=$ Conversion of $\mathrm{C}_{4} \mathrm{H}_{10}$ selectivity of MA

\subsection{Catalysts Characterization}

The crystalline phase of all precursors and activated VPO catalysts were analyzed by employing the X-ray diffractometer (XRD) (Rigaku Smart Lab (9) X-ray powder diffractometer equipped with the monochromatic $\mathrm{x}$-ray light and constant divergence slit) with $\mathrm{Cu} \mathrm{K} \alpha$ radiation $(\lambda=0.15418 \mathrm{~nm})$, the scanned range of $2 \theta$ is between $5^{\circ}$ and $70^{\circ}$ at a scanning rate of $15^{\circ} \mathrm{min}^{-1}$.

Fourier transform infrared spectroscopy (FTIR, Thermal Electron Corporation) was then used to characterize the structure of all the catalysts, in which these catalysts were treated with anhydrous $\mathrm{KBr}$ standard method.

The catalyst phases were further confirmed by adopting Raman spectra instrument (LabRAM HR8000; Horiba Jobin Yvon, France). The beam of $532 \mathrm{~nm}$ wavelength of a solidstate laser was used as excitation source for this system and the scanned range was between 500 and $1800 \mathrm{~cm}^{-1}$. The Raman spectra were recorded in the Stokes regime.
The micro morphologies structures of the samples were also measured by scanning electron microscope (SEM, Hitachi SUB8020) instrument, where the voltage was operated at $20 \mathrm{kV}$. All the samples were pretreated by the $\mathrm{Au}$ sputtering treatment.

The thermogravimetric (TG; TG209F1 thermal analyzer) and differential thermogravimetric analysis (DTA) instrument were adopted to measure the weight loss temperature and phase transformation process. The VPO precursors having grain size 10-20 $\mu \mathrm{m}$ (around $5 \mathrm{mg}$ of sample without pre-treatment) were heated from ambient temperature to $800{ }^{\circ} \mathrm{C}$ at the rate of $10{ }^{\circ} \mathrm{C} \cdot \mathrm{min}^{-1}$ in a $\mathrm{N}_{2}$ flow of $40 \mathrm{~mL} \cdot \mathrm{min}^{-1}$.

$\mathrm{H}_{2}$ temperature-programmed reduction $\left(\mathrm{H}_{2}-\mathrm{TPR}\right)$ instrument was employed to analyze the reduction property of all the activated catalysts, the measurements were carried out in a quartz tube of $4 \mathrm{~mm}$ in diameter with loading a $80 \mathrm{mg}$ sample, where the temperature was increased from 50 to $850{ }^{\circ} \mathrm{C}$ at a rate of $10{ }^{\circ} \mathrm{C} \mathrm{min}-1$ under a $5 \% \mathrm{H} / \mathrm{Ar}$ mixture flowing at $30 \mathrm{~mL} \mathrm{~min}^{-1}$.

The chemistry properties on the surface of catalysts were characterized by using X-ray photo electron spectroscopy (XPS, ESCALAB 250Xi electron spectrometer equipped with double detector system of multichannel photo multiplier plus two dimensional array detector, Thermo Fisher Scientific) with $300 \mathrm{~W} \mathrm{Al} \mathrm{K \alpha}$ radiation. For the analysis, the $\mathrm{C} 1$ peak position was set at $284.6 \mathrm{eV}$ and used as reference to calibrate the other peaks while the fitting of the XPS peaks was done by least-squares using Lorentzian-Gaussian peak shapes.

\section{Results and Discussion}

\subsection{Catalyst Characterization}

XRD analysis was carried out to investigate the crystalline structure of all the samples and the results were shown in Fig. 1. Figure 1a illustrated that all the VPO precursors
Fig. 1 XRD patterns of VPO a precursors, $\mathbf{b}$ activated VPO
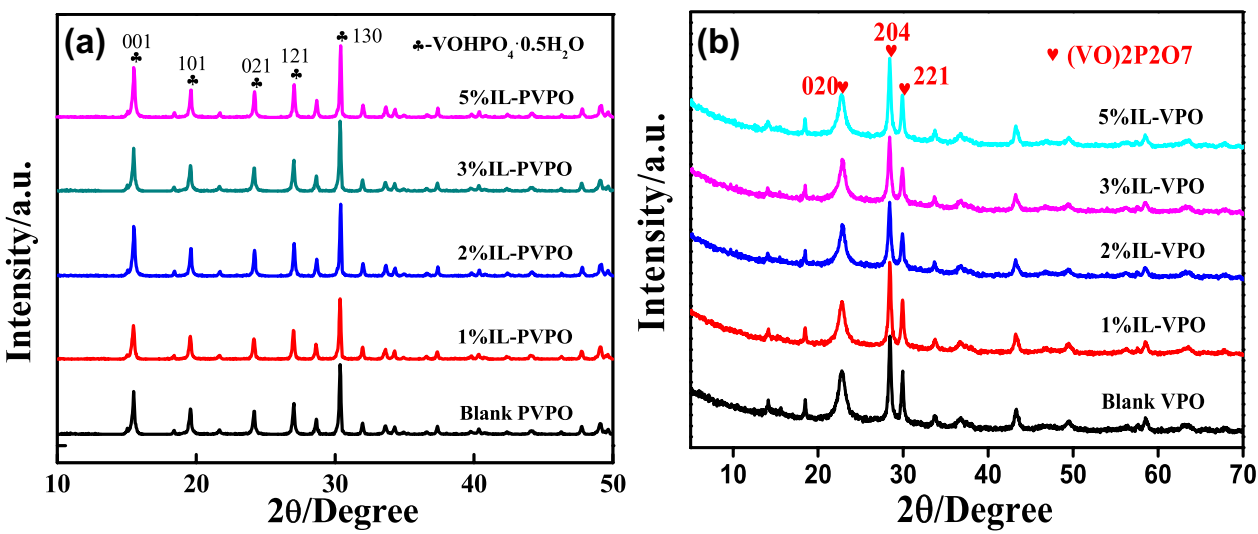
showed only the patterns of vanadyl hydrogen phosphate hemihydrate phase $\left(\mathrm{VOHPO}_{4} \cdot 0.5 \mathrm{H}_{2} \mathrm{O}\right)$ with the reflections at $2 \theta=15.7^{\circ}, 19.8^{\circ}, 24.3^{\circ}, 27.2^{\circ}$ and $30.6^{\circ}$, which corresponds to the (001), (101), (021), (121) and (130) planes (JCPDS \#34-1381), respectively. This founding implied that adding ILs with different contents have not created any variation in crystalline structure for all the precursors. However, an obvious effect on relative integral intensities and full width at half maximum (FWHM) were observed as shown in Table 1. It is founding that the VPO precursors with IL addition exhibit a smaller relative integral intensity of the (001) and (130) planes than the Blank-PVPO, especially for 1\%IL-PVPO and 5\%IL-PVPO, which is different with conventional method that the addition of metal dopant will remarkably increase the $\mathrm{I}_{(001) /(130)}$ values [27]. This phenomenon indicated that IL is able to adjust the growth behavior of the crystal plane of VPO precursors, the same results were also reported in our previous work [26]. In addition to this, a change in IL addition contents from 1 to $3 \%$ was found to show a great increase in $\mathrm{I}_{(001) /(130)}$ value for IL-PVPO, whereas when the addition amount was higher than $3 \%$, the $\mathrm{I}_{(001) /(130)}$ value of the catalyst displays a slight downward trend. Generally, the (001) plane in $\mathrm{VOHPO}_{4} \cdot 0.5 \mathrm{H}_{2} \mathrm{O}$ is usually considered as main active face to be topologically transformed into the (020) plane of $(\mathrm{VO})_{2} \mathrm{P}_{2} \mathrm{O}_{7}$ under activation conditions [36, 37], therein the optimized 3\%IL-PVPO catalyst with high relative integral intensity $\mathrm{I}_{(001) /(130)}$ value might be beneficial for the enhancement in catalytic activity. Interestingly, Table 1 also demonstrated that IL addition increased the FWHM of (001) for IL-PVPO by comparison with the blank-PVPO, implying that the IL-PVPO might possess the smaller crystallite size in the (001) plane since the crystallite size is usually inversely proportional to the FWHM. Theoretically, the smaller crystallite size is possibly conducive to lattice oxygen mobility to enhance the catalyst performance [38].

Figure $1 \mathrm{~b}$ presented the XRD profiles of activated VPO catalysts. The patterns demonstrated that the main crystalline phase of all the catalysts is $(\mathrm{VO})_{2} \mathrm{P}_{2} \mathrm{O}_{7}$, its characterized diffraction reflections at $2 \theta=23^{\circ}, 28.6^{\circ}$ and $30.1^{\circ}$ can be well related to the (020), (204), and (221) planes (JCPDS \#34-1381), respectively. Any extra reflections of phosphorus in VPO were not detected. Table 2 summarized the

Table 1 XRD data of the VPO precursors

\begin{tabular}{lll}
\hline VPO precursors & $\mathrm{I}_{(001) /(130)}$ & $\mathrm{FWHM}(001))^{\circ}$ \\
\hline Blank-PVPO & 1.155 & 0.199 \\
1\%IL-PVPO & 0.850 & 0.246 \\
2\%IL-PVPO & 0.916 & 0.237 \\
3\%IL-PVPO & 1.072 & 0.245 \\
5\%IL-PVPO & 0.951 & 0.220 \\
\hline
\end{tabular}

Table 2 XRD data of the activated VPO

\begin{tabular}{lll}
\hline Catalyst & $\mathrm{I}_{(020) /(204)}$ & $\operatorname{FWHM}(020) /^{\circ}$ \\
\hline Blank-VPO & 0.893 & 0.745 \\
$1 \% \mathrm{IL}-\mathrm{VPO}$ & 0.798 & 0.652 \\
$2 \% \mathrm{IL}-\mathrm{VPO}$ & 0.995 & 0.621 \\
$3 \% \mathrm{IL}-\mathrm{VPO}$ & 1.149 & 0.610 \\
$5 \% \mathrm{IL}-\mathrm{VPO}$ & 0.921 & 0.707 \\
\hline
\end{tabular}

$I_{(020)} / I_{(204)}$ intensity and FWHM of (020) plane. Surprisingly, the $2 \% \mathrm{IL}-\mathrm{VPO}$ and $3 \% \mathrm{IL}-\mathrm{VPO}$ catalysts show higher relative integral intensity of $\mathrm{I}_{(020)} / \mathrm{I}_{(204)}$ compared to the undoped $\mathrm{VPO}$, the $(020)$ plane is generally assumed to be the primary active face of $(\mathrm{VO})_{2} \mathrm{P}_{2} \mathrm{O}_{7}$ and its enhancement means more vanadyl groups would be exposed on the surface of catalyst [26]. Therein, the increase in relative intensity of $I_{(020)} / I_{(204)}$ is directly correlated with the improvement of catalytic performance. As mentioned previously, the (001) plane of $\mathrm{VOHPO}_{4} \cdot 0.5 \mathrm{H}_{2} \mathrm{O}$ in precursor can be converted topologically into the (020) plane of $(\mathrm{VO})_{2} \mathrm{P}_{2} \mathrm{O}_{7}$ [35], yet it also noteworthy that the 3\%IL-VPO catalyst with lower $I_{(001) /(130)}$ value in its precursor gave the higher $I_{(020)} / I_{(204)}$ than the pure VPO catalyst. Obviously, the addition of appropriate IL content could induce the growth of active plane of $(\mathrm{VO})_{2} \mathrm{P}_{2} \mathrm{O}_{7}$ under activation conditions. Unlike the precursors, the FWHM of (020) plane was slightly decreased for the activated IL-VPO compared to the undoped VPO.

Figure 2 showed the FT-IR spectra of all the activated catalysts. As observed, all the peaks in the range of $600-1600 \mathrm{~cm}^{-1}$ displayed the same characteristic vibrations of $(\mathrm{VO})_{2} \mathrm{P}_{2} \mathrm{O}_{7}$. The peaks at $1255.4 \mathrm{~cm}^{-1}$ and $1143.6 \mathrm{~cm}^{-1}$ are mainly ascribed to the asymmetric stretching vibration

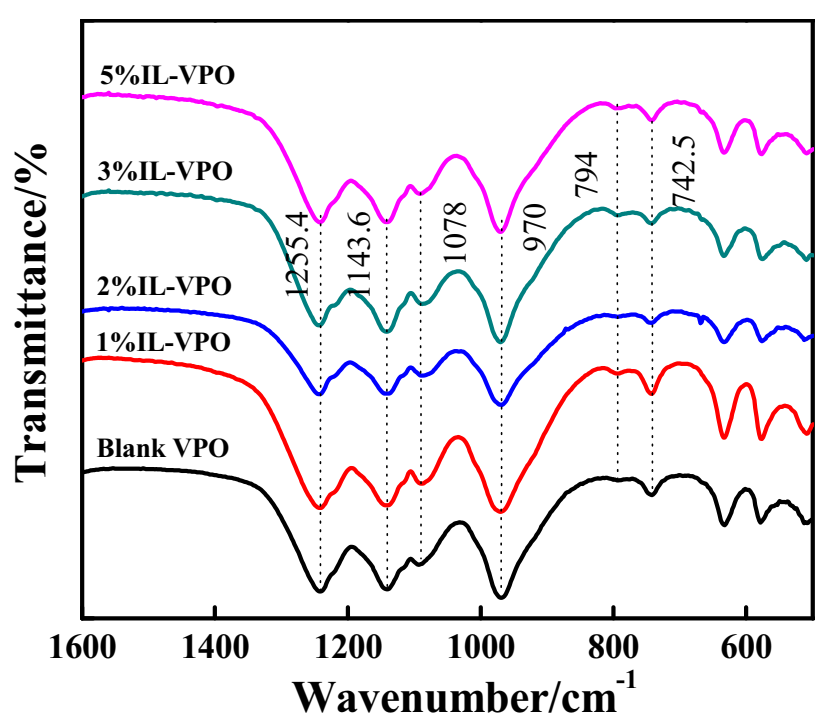

Fig. 2 FT-IR spectra for all the activated catalysts 
band of $\mathrm{PO}_{3}$, while the band at $1078 \mathrm{~cm}^{-1}$ is linked to $\mathrm{PO}_{3}$ symmetric stretching vibration [27]. Also, the characteristic band appearing at $742.5 \mathrm{~cm}^{-1}$ corresponds to the $\mathrm{P}-\mathrm{O}-\mathrm{P}$ symmetrical stretching, and $\mathrm{V}-\mathrm{P}(\mathrm{O}=\mathrm{V})$ stretching vibration band was also detected at $794 \mathrm{~cm}^{-1}$ [39]. It suggests that the introduction of IL has not caused the variation in the structure of VPO catalyst, which is consistent with the XRD characterization.

Raman spectroscopic analysis was further conducted in this section to confirm the crystal structure of activated catalysts. As observed in Fig. 3, all the samples show the main

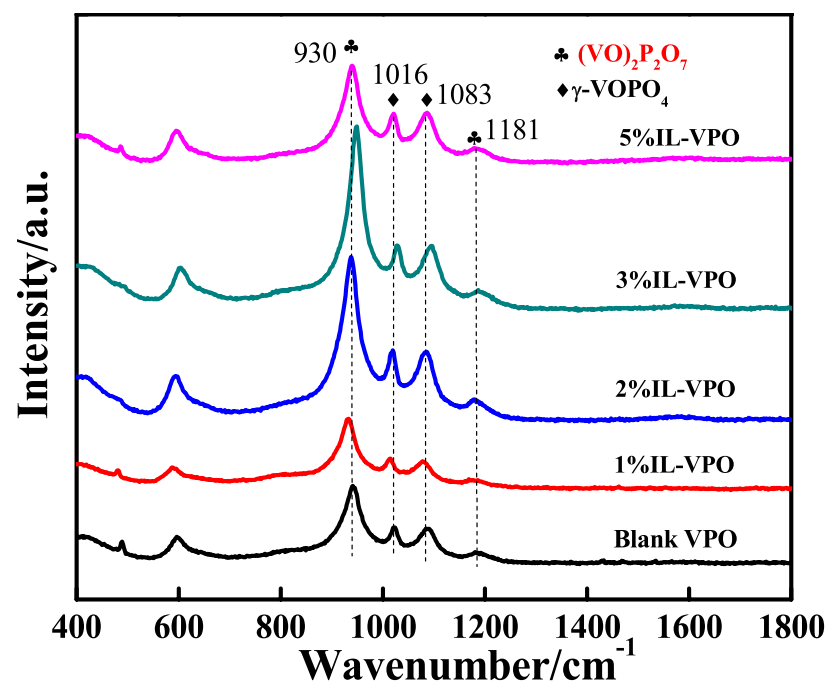

Fig. 3 Raman spectra of activated VPO catalysts characteristic bands attributed to $(\mathrm{VO})_{2} \mathrm{P}_{2} \mathrm{O}_{7}$, during which the strong vibration peaks at 930 and $1181 \mathrm{~cm}^{-1}$ are correspond to the asymmetric $\mathrm{P}-\mathrm{O}-\mathrm{P}$ and $\mathrm{V}-\mathrm{O}-\mathrm{P}$ stretching of (VO) ${ }_{2} \mathrm{P}_{2} \mathrm{O}_{7}$, respectively [40]. It can be clearly observed that the intensity of both peaks height enhanced initially and then weakened with the increasing of amounts of IL, indicating that the addition of IL induce the formation of $(\mathrm{VO})_{2} \mathrm{P}_{2} \mathrm{O}_{7}$, this phenomenon is in accordance with the XRD results. Besides, the weak vibration bands appearing at 1016 and $1083 \mathrm{~cm}^{-1}$ can be linked to a small amount of $\gamma$-VOPO4, which was not detected in XRD analysis due to the low content or high dispersion of this $\mathrm{V}^{5+}$ phase [35]. The existence of this phase usually has a significant impact on the catalytic activity and MA selectivity even though it has always been a controversial issue for decades [41, 42]. Some reports also proposed that $\mathrm{V}^{5+}$ species usually play an important role in hydrogen abstraction from n-butane and a synergetic effect of a well-dispersed $\mathrm{V}^{5+}$ phase leads to the enhancement of the n-butane activation and selectivity to MA $[9,26]$.

The micromorphologies of all the precursors and activated catalysts were characterized in detail as shown in Fig. 4. The blank PVPO is mainly composed of rose-like clusters stacked by sheet crystallites structures with lamellar thickness around 0.12um (Fig. 4a), the sheet structure is conductive to the exposure of (001) crystal plane of $\mathrm{VOHPO}_{4} \cdot 0.5 \mathrm{H}_{2} \mathrm{O}$ and result in a higher $\mathrm{I}_{(001)} / \mathrm{I}_{(130)}$. While $1 \%$ IL-PVPO almost remains the rose-shape structures with the exception of presenting the trend of irregular sheet stacking (Fig. 4b), the variation in structure is mainly caused by the fact that the addition of small amount of IL might not

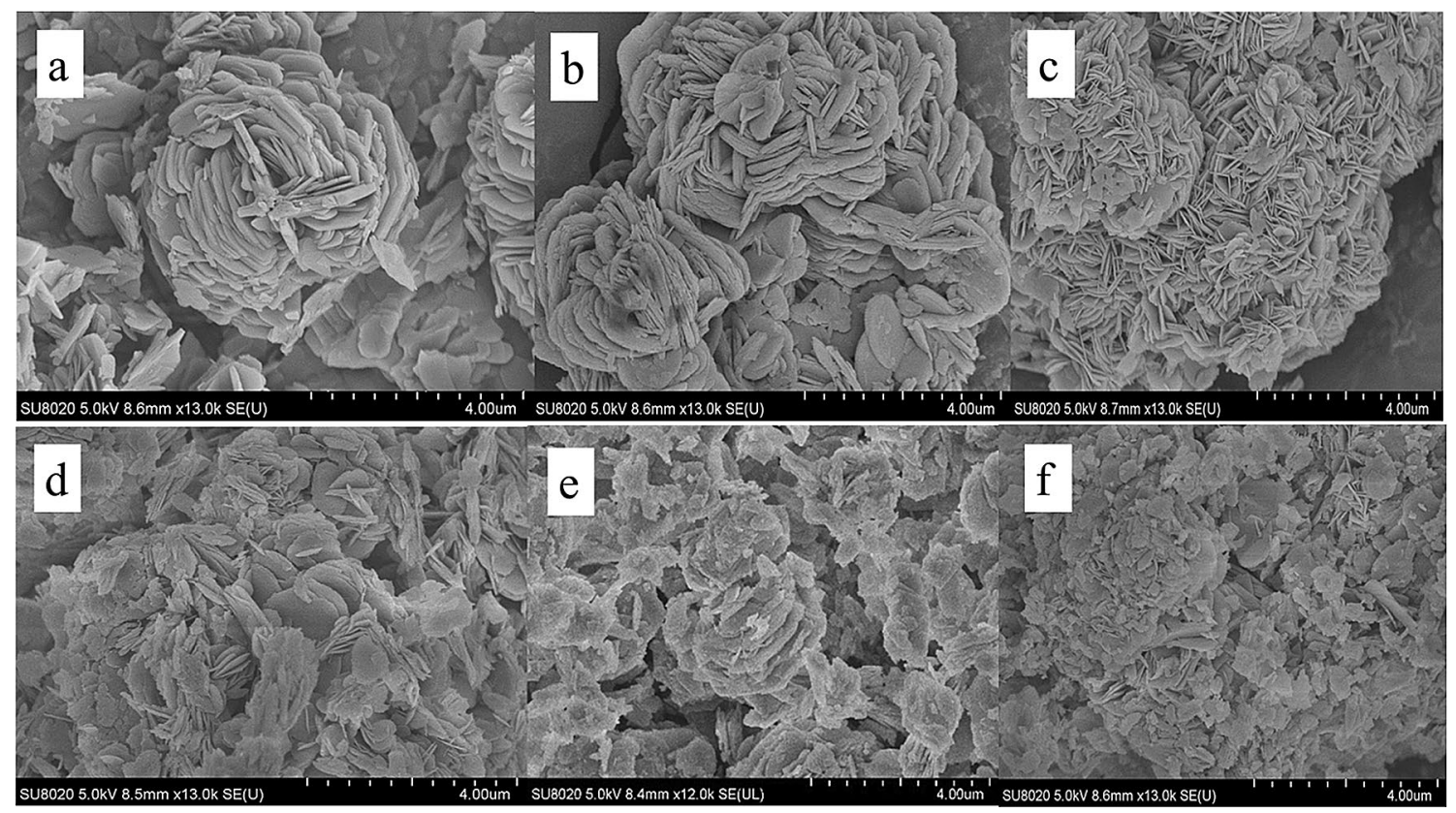

Fig. 4 SEM of VPO precursors and catalysts: a Blank-PVPO, b 1\%IL-PVPO, c 3\%IL-PVPO, d 5\%IL-PVPO, e Blank VPO, f $3 \%$ IL-VPO 
achieve their full potential on the interaction with organic solvent. Interestingly, the 3\%IL-PVPO exhibit a vertically intercrossed slice structure with smaller lamellar thickness around $0.08 \mu \mathrm{m}$ (Fig. 4c), meaning that the micromorphology of $\mathrm{VOHPO}_{4} \cdot 0.5 \mathrm{H}_{2} \mathrm{O}$ has been changed significantly by introducing IL even though there is no crystalline phase change as presented in $\mathrm{XRD}$, this phenomenon possibly attributed to the inducted effect that $[\mathrm{BMIM}] \mathrm{PF}_{6}$ acting as a structure-directing agent and promoters influence the nucleation and growth of crystals by interacting with substrate molecule [26]. However, the regularly intercrossed slice structure was further destroyed and its lamellar structure was disorderly accumulated again when the more IL was introduced in VPO precursors, as shown in Fig. 4d. Extensive research reported that the morphology of final catalyst will be influenced by precursor, therein the SEM of activated VPO were also analyzed. Obviously, the blank VPO maintains its sheet stack structure (Fig. 4e) and show a tendency of sheet agglomeration. For 3\%IL-VPO, the intercrossed slice structure of its precursor was apparently collapsed into tiny sheet crystallize with regular structure after activation accompanied by the removing of IL (Fig. 4f), this variation in morphologies significantly enlarged the specific surface area of the catalyst. Generally, the plate-like crystallites primarily consist of agglomerates of $(\mathrm{VO})_{2} \mathrm{P}_{2} \mathrm{O}_{7}$ platelets that preferentially expose $(020)$ crystal planes [16, $18]$. Therefore, the catalysts possess the more (020) active surface than others because of its high specific surface area, this explained why the $3 \% \mathrm{IL}-\mathrm{VPO}$ gave the higher $\mathrm{I}_{(020)} / \mathrm{I}_{(204)}$ than the blank VPO.

TG and DTA were performed in this section to explore the decomposition temperature for the blank PVPO and 3\%IL-PVPO. As observed in Fig. 5, both precursors underwent the three similar weightlessness stages. The first stage in the weight loss occurred below $220^{\circ} \mathrm{C}$ is primary ascribe to the removal of physical-adsorption water. While the second stage between 220 and $460{ }^{\circ} \mathrm{C}$ was mainly due to the crystalline phase conversion from $\mathrm{VOHPO}_{4} \cdot 0.5 \mathrm{H}_{2} \mathrm{O}$ to $(\mathrm{VO})_{2} \mathrm{P}_{2} \mathrm{O}_{7}$ and the decomposition of alcohols remained in the crystalline layer of precursors. Whereas the weight loss was observed to show a slight and even inconspicuous decrease above $460^{\circ} \mathrm{C}$ in the final step, which could be linked to the dehydration as well as the formation of crystal defects [43]. In addition, TG profile of blank [BMIM] $\mathrm{PF}_{6}$ is recorded as shown in Fig. 5c. Obviously, IL as structure directing agent and promoters during the VPO precursor preparation occur the decomposition in the activation and reaction process, which lead to the higher endothermic signal from the DTA curves for the 3\%IL-PVPO by comparison with Blank-PVPO. Based on the TG-DTA analysis results shown in Fig. 5, it can be seen that central decomposition temperature of $3 \% \mathrm{IL}-\mathrm{PVPO}$ is $454{ }^{\circ} \mathrm{C}$, which is higher than that of the undoped VPO precursor. Regarding of this
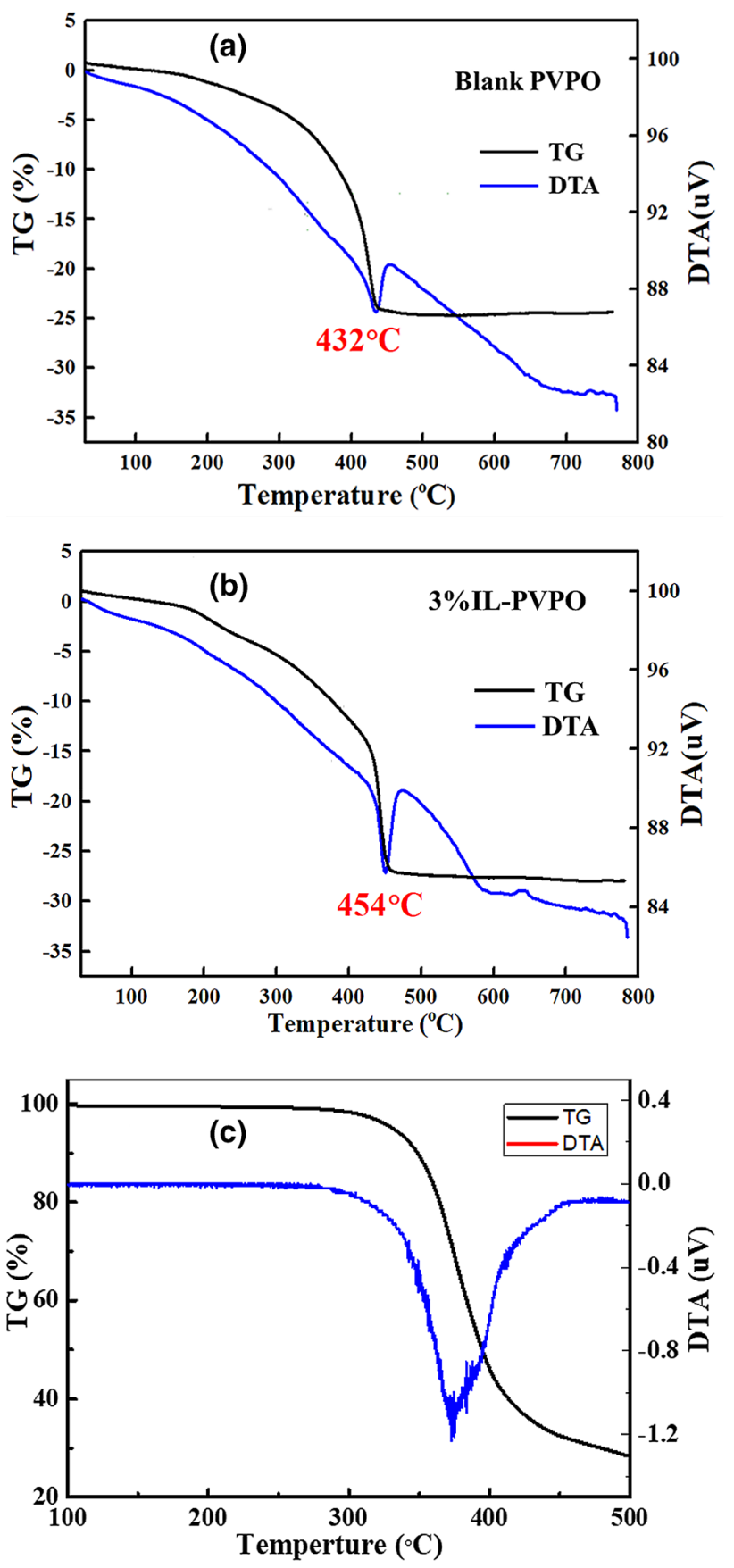

Fig. 5 TG and DTA analysis for a blank PVPO, b 3\%IL-PVPO and c $\left[\mathrm{BMIM}^{2} \mathrm{PF}_{6}\right.$

phenomenon, a conclusion can be basically drawn that the addition of IL during the preparation of VPO significantly brought up its transition temperature of crystalline phase, implying that the 3\%IL-VPO probably have better crystal phase stability, which is also in good agreement with our previous report [35].

In addition, the specific surface areas of all the catalysts were measured by BET and the results were listed in Table 3 . 

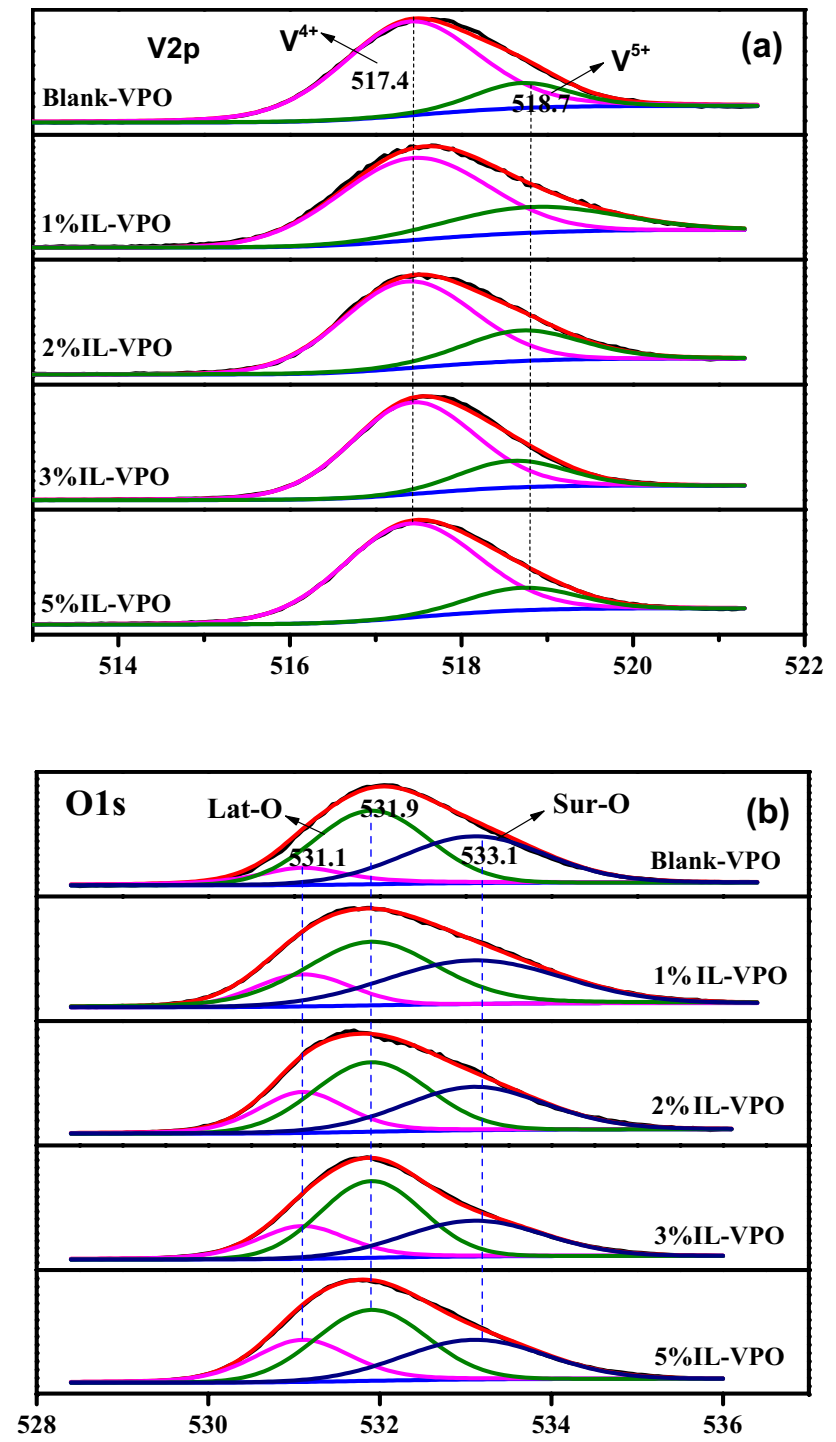

Fig. 6 XPS peaks of activated catalysts

The changes can be seen clearly that adding the IL with different amount into the VPO increased the specific surface area of the catalyst as compared to the pure VPO, and the specific surface area of VPO was enhanced gradually with the increase in IL addition amount, whereas when the introduction of IL is higher than 3\%, the specific surface area of catalyst exhibit a downward trend. This finding implied that the introduction of IL has a significant impact on the structural morphology and crystallite size of VPO.

The VPO surface chemistry on oxidation state of V and oxygen species as well as elemental composition were also studied by using XPS as shown in Fig. 6, Fig. 6a shows the binding energies of the $\mathrm{V} 2 \mathrm{p}_{3 / 2}$ for all the samples and two peaks corresponding to the $\mathrm{V}^{5+}$ and $\mathrm{V}^{4+}$ were detected at 518.7 and $517.4 \mathrm{eV}$, respectively [44-47], this finding reveal that all the catalysts contains $\mathrm{V}^{5+}$ and $\mathrm{V}^{4+}$ species, which is also evidenced to the Raman results. The presence of appropriate proportion of $\mathrm{V}^{5+}$ species in VPO was reported to benefit for the n-butane selective oxidation to MA. Besides, the binding energies of O1s on VPO surface as shown in Fig. $6 \mathrm{~b}$ was in the range of 528.5-533.8 eV [44, 47]. As reported, the binding energies peak appearing at 531 and $531.9 \mathrm{eV}$ are primarily ascribed to lattice oxygen ions (Lat-O) on the surface [44, 48, 49], while the $533.1 \mathrm{eV}$ peak linked to surface hydroxide ions and carbonate (Sur-O) [47]. The percentage of oxygen species (Lat-O/Sur-O) was also calculated based on the deconvolution of $\mathrm{O} 1 \mathrm{~s}$ peaks and summarized into the Table 3. Generally, Lat-O is considered as the main active oxygen source for selective conversion of n-butane, while the Sur-O easily result in the over-oxidation to undesired products, thus enhancing the amount of lattice oxygen in VPO is helpful to the improvement of catalytic performance [35]. According to the differ in binding energies (BEs) of $\mathrm{V} 2 \mathrm{p}_{3 / 2}$ and $\mathrm{O} 1 \mathrm{~s}$ peaks, the average oxidation state of $\mathrm{V}$ was also calculated [50] and the results were listed in Table 3. As observed, the oxidation state of V for IL-VPO exhibits an increase trend with the continuous increase of IL concentration, which are all lower than that of blank VPO. An obvious conclusion can be drawn that the IL is able to adjust the surface valence state, having an important impact on catalytic behavior.

Furthermore, the surface P/V ratio as an important indicator to affect catalytic performance was also

Table 3 BET and XPS characterization data

\begin{tabular}{|c|c|c|c|c|c|c|c|c|c|}
\hline \multirow[t]{2}{*}{ Catalysts } & \multirow[t]{2}{*}{$\mathrm{S}_{\mathrm{BET}}\left(\mathrm{m}^{2} / \mathrm{g}\right)$} & \multirow[t]{2}{*}{$\mathrm{V} 2 \mathrm{p}_{3 / 2}$} & \multirow[t]{2}{*}{$\mathrm{O} 1 \mathrm{~s}$} & \multicolumn{2}{|c|}{ Peak area of Lat-O ${ }^{a}$} & \multirow{2}{*}{$\begin{array}{l}\text { Peak area of Sur-O } \\
533.1 \mathrm{eV}\end{array}$} & \multirow[t]{2}{*}{ Lat-O/Sur-O } & \multirow[t]{2}{*}{$\operatorname{Vox}^{\mathrm{b}}$} & \multirow[t]{2}{*}{$\mathrm{P} / \mathrm{V}$} \\
\hline & & & & $531.1 \mathrm{eV}$ & $531.9 \mathrm{eV}$ & & & & \\
\hline Blank-VPO & 13.25 & 517.49 & 531.69 & $11,426.63$ & $44,442.96$ & $36,201.65$ & 1.54 & 4.16 & 1.65 \\
\hline $1 \%$ IL-VPO & 18.56 & 517.59 & 531.95 & $18,085.81$ & $54,250.75$ & $44,382.84$ & 1.63 & 4.06 & 1.67 \\
\hline $2 \% \mathrm{IL}-\mathrm{VPO}$ & 28.09 & 517.59 & 531.87 & $19,842.34$ & $54,842.56$ & $40,422.54$ & 1.85 & 4.09 & 1.69 \\
\hline $3 \% \mathrm{IL}-\mathrm{VPO}$ & 31.43 & 517.64 & 531.92 & $34,346.34$ & $77,889.7$ & $49,568.08$ & 2.26 & 4.10 & 1.71 \\
\hline $5 \%$ IL-VPO & 21.02 & 517.51 & 531.75 & $40,772.92$ & $69,367.28$ & $49,517.29$ & 1.78 & 4.14 & 1.75 \\
\hline
\end{tabular}

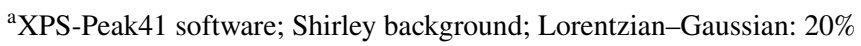

${ }^{\mathrm{b}} \mathrm{Vox}=13.82-0.68[\mathrm{O} 1 \mathrm{~s}-\mathrm{V} 2 \mathrm{p} 3 / 2]$ 
presented in Table 3. Compared with the blank VPO (P/V ratio 1.65), the IL-doped VPO can be observed to display higher surface $\mathrm{P} / \mathrm{V}$ ratio, corresponding to 1.67 , $1.69,1.71$ and 1.75 , respectively. The result implied that IL modified the vanadium oxidation state and elemental composition on the surface of catalyst by the hydrogen bonding interaction between the IL and substrates molecular in the preparation of VPO even though its structure decomposes under high-temperature reaction condition (as shown in Fig. 5). This finding is greatly significant because the phosphorus surface enrichment in VPO is generally believed to be responsible for stabilizing the $\mathrm{V}^{4+}$ and isolating the active phase [25, 32]. However, excessive surface phosphorus also could lead to the overoxidation to $\mathrm{CO}_{\mathrm{x}}[51]$.

$\mathrm{H}_{2}$-TPR was employed in this section to in-depth investigate the influence of IL on redox properties. As illustrated in Fig. 7, two reduction spectrums corresponding to different oxygen species were emerged for all the activated VPO catalysts. For blank VPO, the both peaks were detected at 507.4 and $730.5{ }^{\circ} \mathrm{C}$, respectively. The former weak peak is mainly assigned to the removal of $\mathrm{O}^{2-}$ oxygen specie linked to the $\mathrm{V}^{5+}$ phase, while the latter strong one is attributed to $\mathrm{O}^{-}$oxygen specie related to the $\mathrm{V}^{4+}$ phase [52]. Generally, the active phase $(\mathrm{VO})_{2} \mathrm{P}_{2} \mathrm{O}_{7}$ would be reduced into $\mathrm{VPO}_{4}$ in $\mathrm{H}_{2}$ atmosphere at $730.5^{\circ} \mathrm{C}$. However, the both peaks for IL-doped VPO catalysts are all switched to the lower temperature in contrast to the blank VPO, this phenomenon demonstrated

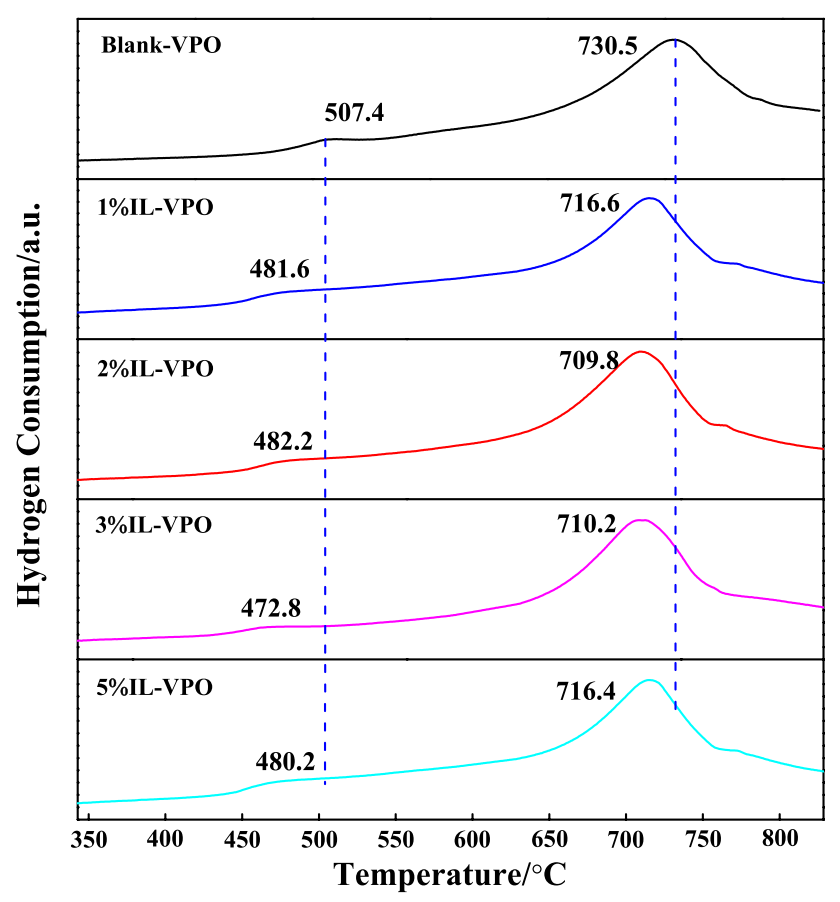

Fig. 7 H2-TPR analysis of all the activated catalysts that the reducibility ability of vanadium valence for these catalysts were remarkably enhanced by the introduction of IL. Besides, the amount of oxygen species removed associated with both $\mathrm{V}^{5+}$ and $\mathrm{V}^{4+}$ phases were calculated and listed in Table 4. As observed, the catalysts doped by IL shows more amount of reaction oxygen for the n-butane reducibility than the blank VPO, this finding further reveals that IL dopant generate a positive impact on strengthening the storages and transfer of oxygen species. The calculation on oxygen ratio removed from $\mathrm{V}^{5+} /$ $\mathrm{V}^{4+}$ phase from Table 4 presented that the modification of VPO by IL notably increase the amount of oxygen specie corresponding to $\mathrm{V}^{4+}$, implying that the exposure to the active surface of $(\mathrm{VO})_{2} \mathrm{P}_{2} \mathrm{O}_{7}$ after activation is increased. This result was also supported by the Raman and XPS analysis, where the pattern of $(\mathrm{VO})_{2} \mathrm{P}_{2} \mathrm{O}_{7}$ is greatly enhanced by incorporation of IL into VPO. Based on the $\mathrm{H}_{2}$-TPR data, the relationship between the valence state of $\mathrm{V}\left(\mathrm{Vo}_{\mathrm{X}}\right)$ from XPS and oxygen species amount was correlated as shown in Fig. 8. Obviously, the variation trend of Vox for all the VPO catalysts corresponds to the change of oxygen species removal ratio of $\mathrm{V}^{5+}$ / $\mathrm{V}^{4+}$. However, 3\%IL-VPO having the Vox of 4.10 possess the largest total oxygen removal amount, indicating the catalyst has great potential to show excellent catalytic performance.

\subsection{Catalytic Performance}

The catalytic evaluation for all VPO catalysts were tested in the fixed bed microreactor for $n$-butane selective oxidation to MA and the corresponding experimental results were displayed in Table 5. By comparison with the undoped VPO showing n-butane conversion $74.6 \%$ and MA yield $49.4 \%$, the introduction of IL in the synthesis of VPO enhanced n-butane conversion and MA selectivity simultaneously under the same reaction conditions, which is different from the results of previous research that the MA selectivity would be reduced with enhanced n-butane conversion [18]. Besides, the n-butane conversion for the promoted VPO catalysts were increased gradually (i.e. $75.4 \%, 83.4 \%$, $88.1 \%$ and $82.4 \%$ for $1 \% \mathrm{IL}-\mathrm{VPO}, 2 \% \mathrm{IL}-\mathrm{VPO}, 3 \% \mathrm{IL}-\mathrm{VPO}$ and 5\%IL-VPO, respectively.) with the increase of IL dosage but MA selectivity were decreased continuously (i.e. $69.2 \%, 68.5 \%, 67.2 \%$ and $68.7 \%$ for $1 \% \mathrm{IL}-\mathrm{VPO}, 2 \% \mathrm{IL}-$ VPO, 3\%IL-VPO and 5\%IL-VPO, respectively.), which is also accompanied by the change in COx yield accordingly. During the catalysts studied, the catalyst $3 \%$ IL-VPO shows the highest MA yield of 59.2\% under the same conditions, which recorded to be $9 \%$ higher than that of blank VPO catalyst. 
Table 4 The reduction properties of all the catalysts

\begin{tabular}{|c|c|c|c|}
\hline Catalyst & $\mathrm{T}\left({ }^{\circ} \mathrm{C}\right)$ & $\begin{array}{l}\text { O atoms removed } \\
(\mathrm{mmol} / \mathrm{g})\end{array}$ & $\begin{array}{l}\text { Ratio for oxygen } \\
\text { removed from } \mathrm{V}^{5+} / \\
\mathrm{V}^{4+}\end{array}$ \\
\hline \multicolumn{4}{|l|}{ Blank-VPO } \\
\hline 1 & 507.4 & 0.786 & \multirow[t]{3}{*}{0.041} \\
\hline 2 & 730.5 & 19.339 & \\
\hline Total oxygen atoms desorbed & & 20.125 & \\
\hline \multicolumn{4}{|l|}{$1 \%$ IL-VPO } \\
\hline 1 & 481.6 & 0.121 & \multirow[t]{3}{*}{0.006} \\
\hline 2 & 716.6 & 21.493 & \\
\hline Total oxygen atoms desorbed & & 21.614 & \\
\hline \multicolumn{4}{|l|}{$2 \%$ IL-VPO } \\
\hline 1 & 482.2 & 0.258 & \multirow[t]{3}{*}{0.011} \\
\hline 2 & 709.8 & 22.755 & \\
\hline Total oxygen atoms desorbed & & 23.013 & \\
\hline \multicolumn{4}{|l|}{ 3\%IL-VPO } \\
\hline 1 & 472.8 & 0.354 & \multirow[t]{3}{*}{0.015} \\
\hline 2 & 710.2 & 23.884 & \\
\hline Total oxygen atoms desorbed & & 24.238 & \\
\hline \multicolumn{4}{|l|}{$5 \%$ IL-VPO } \\
\hline 1 & 480.2 & 0.489 & \multirow[t]{3}{*}{0.023} \\
\hline 2 & 716.4 & 21.362 & \\
\hline Total oxygen atoms desorbed & & 21.851 & \\
\hline
\end{tabular}

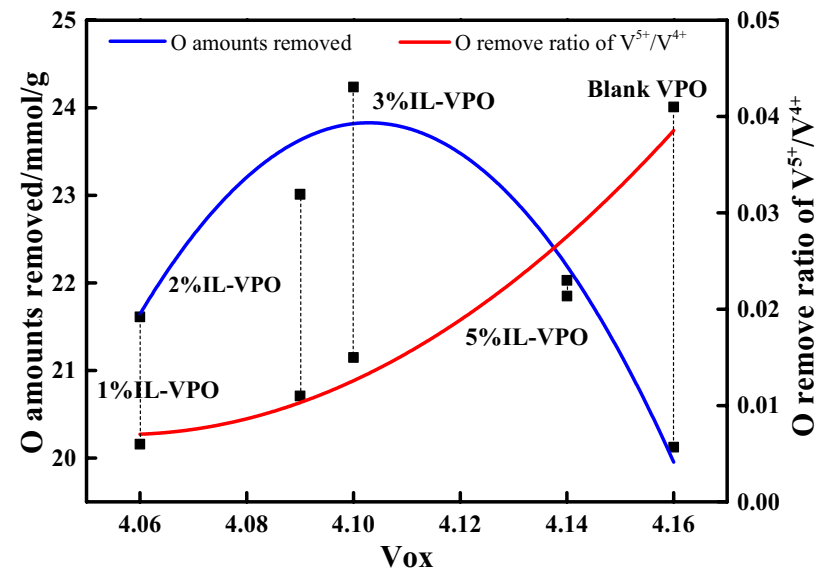

Fig. 8 Correlation between the Vox and oxygen species amount from $\mathrm{H}_{2}$-TPR $\left(\mathrm{T}=420{ }^{\circ} \mathrm{C}, \mathrm{GHSV}=2000 \mathrm{~h}^{-1}, \mathrm{C}_{4} \mathrm{H}_{10} / \mathrm{air}=1.5 / 98.5\right)$

\subsection{Discussion}

Generally, the excellent catalytic activity of IL-VPO developed is primarily attributed to its morphology structure and specific surface area. As observed from SEM in Fig. 4, the micromorphology of VPO catalyst was changed remarkably by the introduction of IL as structural directing agent and template, all the IL-VPO catalysts exhibit the higher specific surface area than blank VPO, which can be confirmed by
Table 5 Catalytic performance of undoped and IL-doped VPO catalysts

\begin{tabular}{llllll}
\hline Catalysts & $\begin{array}{l}\text { n-butane con- } \\
\text { version (\%) }\end{array}$ & \multicolumn{3}{l}{ Selectivity (\%) } & Yield $_{\mathrm{MA}}(\%)$ \\
\cline { 3 - 5 } & & $\mathrm{MA}$ & $\mathrm{CO}$ & $\mathrm{CO}_{2}$ & \\
\hline Blank-VPO & 74.6 & 66.2 & 22.3 & 11.5 & 49.4 \\
$1 \% \mathrm{IL}-\mathrm{VPO}$ & 75.4 & 69.2 & 18.3 & 12.5 & 52.2 \\
2\%IL-VPO & 83.4 & 68.5 & 19.1 & 12.4 & 57.1 \\
3\%IL-VPO & 88.1 & 67.2 & 21.1 & 11.7 & 59.2 \\
5\%IL-VPO & 82.4 & 68.7 & 20.8 & 10.5 & 56.6 \\
\hline
\end{tabular}

Conditions: $\mathrm{T}=420^{\circ} \mathrm{C}, \mathrm{GHSV}=2000 \mathrm{~h}^{-1}, \mathrm{C}_{4} \mathrm{H}_{10} / \mathrm{air}=1.5 / 98.5$

BET as shown in Table 3. Particularly, 3\%IL-PVPO shows a vertically intercrossed slice structure with smaller lamellar thickness compared to the rose-like clusters structure of blank PVPO, the morphology structure was further collapsed into tiny sheet crystallize with regular structure after activation, leading to a significant increase in the specific surface area to $31.43 \mathrm{~m}^{2} / \mathrm{g}$. However, the specific surface area was further decreased for 5\% IL-VPO, the main reason is that the introduction of excessive amount of IL cause the destruction of the regularly intercrossed slice structure, resulting in the disordered accumulation of crystal plates and the reduction of the gap between the lamellar structures. In general, the high specific surface area of catalyst is able to increase the number of active sites available per unit 


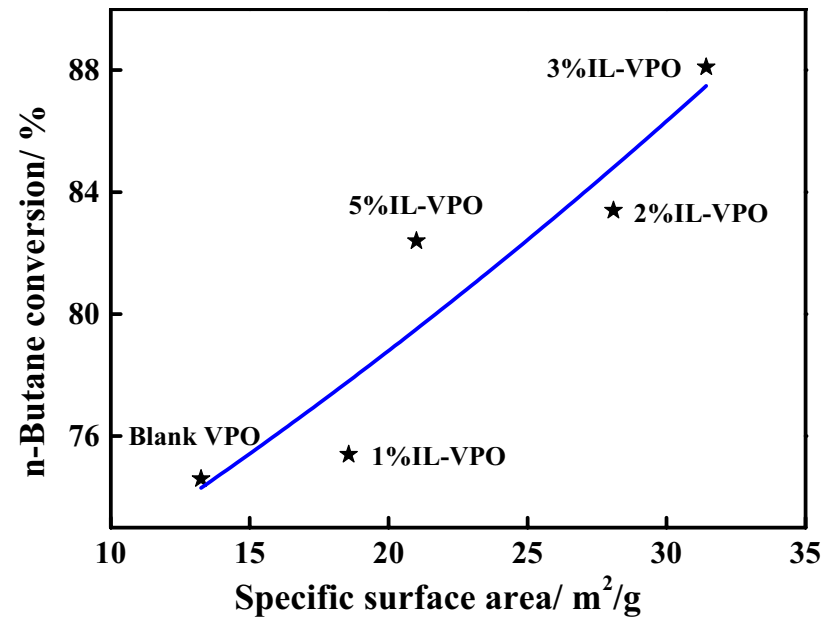

Fig. 9 Correlation between the specific surface area and catalytic activity of the catalyst studied $\left(\mathrm{T}=420^{\circ} \mathrm{C}, \mathrm{GHSV}=2000 \mathrm{~h}^{-1}, \mathrm{C}_{4} \mathrm{H}_{10} /\right.$ air $=1.5 / 98.5)$

mass, which is helpful in enhancing the catalytic activity. As expected from the results in Tables 3 and 5, the specific surface area was observed to be corresponded well with the n-butane conversion for all the VPO catalysts. Therefore, a positive correlation between the catalytic activity and specific surface area was constructed as shown in Fig. 9. Besides, TG-DTA analysis has indicated that IL-VPO process higher transition temperature of crystalline phase than undoped VPO catalyst, suggesting that the IL-VPO has possesses more perfect crystals and stability, which shows a better catalytic activity and MA selectivity to some extent, this conclusion was also confirmed in Table 5.

In addition, IL could also modulate the crystal structure and surface chemical properties of VPO catalysts, which is crucial for the improvement of catalytic activity and selectivity. The XRD analysis from Table 2 have illustrated that adding IL during the preparation of VPO catalysts could promote the formation of active phase $(\mathrm{VO})_{2} \mathrm{P}_{2} \mathrm{O}_{7}$ and enhance the proportion of active plane (020), which can be viewed as the important factors to improve its selective oxidation of n-butane to MA (Table 5). Raman and XPS analysis also further validate the conclusion that IL-VPO possess higher proportion of active phase $\mathrm{V}^{4+}$ specie compared with blank VPO catalyst. Meanwhile, a remarkable variety in surface $\mathrm{P} / \mathrm{V}$ ratio for all catalysts from Table 3 have indicated that the phosphorus surface enrichment in VPO is beneficial for stabilizing the $\mathrm{V}^{4+}$ species and active phase within certain range, but excess surface phosphorus easily causes the overoxidation to COx owing to the possibly strengthened basic sites and decreased weak acid site [51], which explicate the phenomenon well that n-butane conversion and MA yield decline simultaneously for 5\%IL-VPO when P/V ratio on the surface is higher than 1.71, as shown in Fig. 10. Therefore,

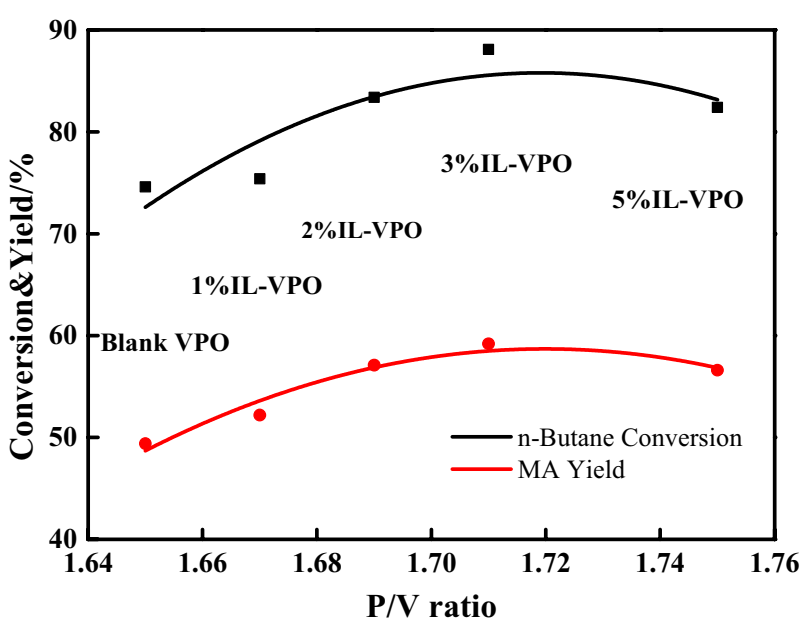

Fig. 10 Correlation between the catalytic performance (n-butane conversion and MA yield) and P/V ratio $\left(\mathrm{T}=420{ }^{\circ} \mathrm{C}, \mathrm{GHSV}=2000 \mathrm{~h}^{-1}\right.$, $\mathrm{C}_{4} \mathrm{H}_{10} / \mathrm{air}=1.5 / 98.5$ )

the appropriate proportion of surface $\mathrm{P} / \mathrm{V}$ ratio is essential for obtaining the high catalytic performance by balancing n-butane conversion and MA selectivity. $\mathrm{H}_{2}$-TPR results further shows that the addition of IL enhanced the reducibility ability of vanadium valence. Meanwhile, the amount of lattice oxygen associated with $\mathrm{V}^{4+}$ species was also increased by IL doped VPO catalysts compared to blank VPO. Correspondingly, the ratio of Lat-O/Sur-O is regarded as the important indicator to evaluate the catalytic selectivity of catalyst. Thus the increase of surface lattice oxygen could improve the transfer efficiency of oxygen, which has a great impact on MA selectivity. Based on the above analysis, introducing IL into VPO are suggested to achieve the better selective oxidation of $n$-butane to MA.

\section{Conclusions}

In present work, the phosphorus-based IL [BMIM]PF 6 was employed firstly as structure directing agent and promoters to synthesis of VPO catalysts for selective oxidation of n-butane to MA. The evaluation results show that the $3 \%$ IL-VPO catalyst shows the maximum MA yield of $59.2 \%$, which is more than 9\% MA yield than that of blank VPO under the same reaction conditions. The detailed characterization on crystal structure and morphology have demonstrated that IL promoted the formation of active phase (VO) ${ }_{2} \mathrm{P}_{2} \mathrm{O}_{7}$ and enhanced the proportion of active plane (020). Meanwhile, the generation of impurity phases including $\gamma-\mathrm{VOPO}_{4}$ was inhibited. The $3 \% \mathrm{IL}-\mathrm{VPO}$ exhibited a vertically intercrossed slice structure morphology with smaller 
lamellar thickness, which notably enhanced the surface area of the VPO catalyst in contrast to the undoped VPO. This is probably due to the hydrogen bonding interaction between the IL and VPO substrate modulate nucleation and growth mechanisms of crystalline grain by IL as structure directing agent. Furthermore, addition of IL also enhanced the average valence state of vanadium and reducibility ability of vanadium valence as well as the amount of lattice oxygen associated with $\mathrm{V}^{4+}$ species, and surface $\mathrm{P} / \mathrm{V}$ ratio was also modulated by IL dopant. All of these are closely associated with the improvement of catalytic performance of VPO catalysts.

Acknowledgements This work was supported by National Key Research and Development Program of China (2017YFA0206803), the National Nature Science Foundation of China (21808223), the Key Programs of the Chinese Academy of Sciences (KFZD-SW-413), the Key Programs of Fujian Institute of Innovation, CAS(FJCXY18020203), Chinese Academy of Sciences, the One Hundred Talent Program of CAS. The authors are grateful for the assistance from teachers $\mathrm{Wu}$ Hui, Wang Ling and Zhou Na of Analysis and Test Center, Institution of Process Engineering, Chinese Academy of Sciences.

Open Access This article is licensed under a Creative Commons Attribution 4.0 International License, which permits use, sharing, adaptation, distribution and reproduction in any medium or format, as long as you give appropriate credit to the original author(s) and the source, provide a link to the Creative Commons licence, and indicate if changes were made. The images or other third party material in this article are included in the article's Creative Commons licence, unless indicated otherwise in a credit line to the material. If material is not included in the article's Creative Commons licence and your intended use is not permitted by statutory regulation or exceeds the permitted use, you will need to obtain permission directly from the copyright holder. To view a copy of this licence, visit http://creativecommons.org/licenses/by/4.0/.

\section{References}

1. Wang P, Fu G, Wan H (2017) ACS Catal 7:4571

2. Zichittella G, Paunovic V, Amrute AP, Perez-Ramirez J (2017) ACS Catal 7:1805

3. Mestl G, Lesser D, Turek T (2016) Top Catal 59:1533

4. Hutchings GJ (2009) J Mater Chem 19:1222

5. Centi G (1993) Catal Today $16: 5$

6. Shen SK, Zhou JP, Zhang FS, Zhou L, Li RJ (2002) Catal Today $74: 37$

7. Taufiq-Yap YH, Asrina SN, Hutchings GJ, Dummer NF, Bartley JK (2011) J Nat Gas Chem 20:635

8. Fan XB, Dummer NF, Taylor SH, Bartleya JK, Hutchings GJ (2012) Catal Today 183:52

9. Wu HY, Jin P, Sun YF, Yang MH, Huang CJ, Weng WZ, Wan HL (2016) J Mol Catal A 414:1

10. Li X, Ji W, Zhao J, Zhang Z, Au C (2006) J Catal 238:232

11. Ivars-Barcelo F, Hutchings GJ, Bartley JK, Taylor SH, Sutter P (2017) J Catal 354:236

12. Wang P, Fu G, Wan H (2017) ACS Catal 7:5544

13. Hutchings GJ, Sananes MT, Sajip S, Kiely CJ, Burrows A, Ellison IJ (1997) Catal Today 33:161

14. Goh CK, Taufiq-Yap YH, Hutchings GJ, Dummer N, Bartley J (2008) Catal Today 131:408
15. Hutchings GJ (1997) Appl Catal 72:1

16. Sajip S, Bartley JK, Burrows A, Sananés-Schulz MT (2001) New J Chem 25:125

17. Sartoni L, Delimitis A, Bartley JK (2006) J Mater Chem 16:4348

18. Taufiq-Yap YH, Nurul Suziana NM, Hussein MZ (2011) Catal Lett 141:136

19. Liu J, Wang F, Gu Z, Xu X (2009) Chem Eng J 151:319

20. Jiang Q, Zhao J, Li XK, Ji WJ, Zhang ZB (2008) Appl Catal A 341:70

21. Lin Z, Weng W, Kiely CJ, Bartley JK, Hutchings GJ (2010) Catal Today 157:211

22. Alhumaimess M, Lin Z, Dummer NF, Taylor SH, Hutchings GJ, Bartley JK (2016) Catal Sci Technol 6:2910

23. Wang X, Xu L, Chen X, Ji W, Yan Q, Chen Y (2003) J Mol Catal A 206:261

24. Carreon MA, Guliants VV (2001) Chem Commun 11:438

25. Li K, He B, Liu JC, Zhang HL, Zhang RR, Liu RX, Song YF, Zhang SJ (2019) Appl Catal A 582:117106

26. Dai F, He B, Liu RX, Zhang SJ (2018) Catal Sci Technol 8:4515

27. He B, Nan L, Li Z, Wen B, Niu J, Liu R (2019) Chem Select 4:662

28. Pries de Oliveira PG, Eon JG, Chavant M, Riché AS, Caldarelli VM, Volta JC (2000) Catal Today 57:177

29. Maiti A, Govind N, Kung P, King-Smith D, Zhang C (2017) J Chem Phys 121:24069

30. Cavani F, Luciani S, Esposti ED, Cortelli C, Leanza R (2010) Chem Eur J 16:1646

31. Conte M, Budroni G, Bartley JK, Taylor SH, Carley AF, Schmidt A, Murphy DM (2006) Science 313:1270

32. Cheng MJ, Goddard WA (2013) J Am Chem Soc 135:4600

33. Cheng MJ, Goddard WA, Fu R (2014) Top Catal 57:1171

34. Lesser D, Mestl G, Turek T (2016) Appl Catal A 510:1

35. He B, Li Z, Zhang H, Dai F, Li K, Liu R, Zhang S (2019) Ind Eng Chem Res 58:2857

36. Guliants VV, Carreon MA (2005) Catalysis 18:1

37. Igarashi H, Tsuji K, Okuhara T, Misono M (1993) J Phys Chem 97:7065

38. Patterson AL (1939) Phys Rev 56:978

39. Bordes E, Courtine P (1979) J Catal 57:236

40. Wu HY, Wang HB, Liu XH, Li JH (2015) Appl Surf Sci 351:243

41. Pierini BT, Lombardo EA (2005) Mater Chem Phys 92:197

42. Benabdelouahab F, Olier R, Guilhaume N, Lefebvre F, Volta JC (1992) J Catal 134:151

43. Hutchings GJ, Ellison IJ (1996) Catal Lett 38:231

44. Yang D, Li D, Yao HY, Zhang GL, Jiao TT, Li CS, Zhang SJ (2015) Ind Eng Chem Res 54:6865

45. Luciani S, Cavani F, Dal Santo V, Dimitratos N, Rossi M, Bianchi CL (2011) Catal Today 169:200

46. Ait-Lachgar K, Tuel A, Brun M, Herrmann JM, Krafft JM, Martin JR, Volta JC, Abon M (1998) J Catal 177:224

47. Abon M, Bere KE, Tuel A, Delichere P (1995) J Catal 156:28

48. Solsona B, Zazhigalov VA, López Nieto JM, Bacherikova IV, Diyuk EA (2003) Appl Catal A 249:81

49. Stoch J, Gablankowskakukucz J (1991) Surf Int Anal 17:165

50. Coulston GW, Herron N, Thompson EA (1996) J Catal 163:122

51. Guo XP, Yang D, Zuo CC, Peng ZJ, Li CS, Zhang SJ (2017) Ind Eng Chem Res 56:5860

52. Taufiq-Yap Y, Goh CK, Hutchings GJ, Bartley JK (2006) J Mol Catal A 260:24

Publisher's Note Springer Nature remains neutral with regard to jurisdictional claims in published maps and institutional affiliations. 